\title{
The effect of experimental warming on the root-associated fungal community of Salix arctica
}

\author{
Kei E Fujimura ${ }^{1}$, Keith N Egger ${ }^{1}$ and Gregory HR Henry ${ }^{2}$ \\ ${ }^{1}$ Ecosystem Science and Management Program, University of Northern British Columbia, Prince George, \\ British Columbia, Canada and ${ }^{2}$ Department of Geography, University of British Columbia, Vancouver, British \\ Columbia, Canada
}

\begin{abstract}
The effect of experimental warming on the root-associated fungal community of arctic willow (Salix arctica) was studied in three distinct habitats at a tundra site in the Canadian High Arctic. Plots were passively warmed for 5-7 years using open-top chambers and compared to control plots at ambient temperature. Fungal communities were assessed using terminal restriction fragment length polymorphisms. We found the following: (1) the root-associated fungal community in these high arctic tundra habitats is highly diverse; (2) site and soil characteristics are the most important drivers of community structure and (3) warming increased the density of different genotypes on individual root sections but has not (yet) affected the composition, richness or evenness of the community. The change in genotype density in the warmed plots was associated with an increase in PCR amplification efficiency, suggesting that increased $\mathbf{C}$ allocation belowground is increasing the overall biomass of the fungal community.
\end{abstract}

The ISME Journal (2008) 2, 105-114; doi:10.1038/ismej.2007.89; published online 25 October 2007

Subject Category: microbial ecosystem impacts

Keywords: arctic willow; dark septate endophytes; mycorrhiza; ribosomal DNA; T-RFLP

\section{Introduction}

By the end of the century, in the absence of significant curtailment in greenhouse gas emissions, models predict that the mean annual temperature north of $60^{\circ} \mathrm{N}$ will increase by $5-7^{\circ} \mathrm{C}$, with the greatest increase occurring during autumn and winter (ACIA, 2005).

Studies of the impacts of experimental warming on arctic tundra have shown that plants respond strongly and rapidly to experimental warming, with changes in plant phenology, reproductive effort and productivity (Henry and Molau, 1997; Arft et al., 1999; Henry, 2002; Walker et al., 2006), and increased carbon allocation to roots (Hill, 2006). At the plant community level, warming caused increased height and cover of deciduous shrubs and graminoids, decreased cover of moss and lichen (Cornelissen et al., 2001), and decreased species diversity and evenness (Hollister et al., 2005; Walker et al., 2006), although the magnitude of these changes depends upon ecosystem type (Van Wijk

Correspondence: KN Egger, Ecosystem Science and Management Program, University of Northern BC, 3333 University Way, Prince George, British Columbia, Canada V2N 4 Z9.

E-mail: egger@unbc.ca

Received 18 July 2007; revised 18 September 2007; accepted 20 September 2007; published online 25 October 2007 et al., 2004) and latitude (Walker et al., 2006). The experimental results support conclusions that increased shrub abundance (Sturm et al., 2001) and tundra greenness (Richter-Menge et al., 2006) in arctic regions are the result of recent warming.

There have been few studies examining how warming affects root-associated microbial communities, even though major impacts of global warming may arise from the influences of increased soil temperature and $\mathrm{CO}_{2}$ concentration on soil processes (Pendall et al., 2004). Increased soil temperature can influence root growth, phenology and architecture, respiration and ion uptake, water and nutrient availability (Pregitzer et al., 2000), but the impacts on soil microbial communities is varied and often unpredictable (Zak et al., 2000). Responses of mycorrhizal fungi to simulated global change factors $\left(\mathrm{CO}_{2}\right.$, warming, shading and fertilization) are also variable, although several studies have found a not unexpected link between increased plant $\mathrm{C}$ allocation belowground and increased mycorrhizal colonization (Staddon et al., 2002; Urcelay et al., 2003; Fitter et al., 2004; Heinemeyer and Fitter, 2004; Olsrud et al., 2004; Clemmensen et al., 2006). Some studies have found that experimental treatments alter mycorrhizal community composition (Rygiewicz et al., 2000; Clemmensen and Michelsen, 2006; Parrent et al., 2006), but these changes are rarely of 
sufficient magnitude to significantly change the overall richness or diversity of the community.

Given the important role of root-associated fungi in nutrient acquisition, we set out to examine the interactions between site and soil characteristics and experimental warming on the composition and diversity of the root-associated fungal community of the ectomycorrhizal dwarf shrub, Salix arctica. Since roots were washed well before characterization, the root-associated fungal community should be dominated by mycorrhizal fungi, dark septate endophytes, hyaline septate endophytes, and possibly root-pathogens. Ectomycorrhizal and ericoid mycorrhizal fungi are important components of arctic systems (Gardes and Dahlberg, 1996), and dark septate endophytes and hyaline septate endophytes are ubiquitous in both alpine and arctic systems (Bledsoe et al., 1990; Gardes and Dahlberg, 1996; Jumpponen, 1999; Cázares et al., 2005). Although the contributions of mycorrhizas to nutrient uptake are well-known (Smith and Read, 1997), the function of dark septate endophytes and hyaline septate endophytes are less clear, as they appear to range from pathogenic to mutualistic (Jumpponen, 2001). Dark septate endophytes have been hypothesized to mimic the role of arbuscular mycorrhizal fungi, which are scarce in the high arctic (Bledsoe et al., 1990). To investigate the potential impact of climate change on root-associated fungal communities, warming experiments were established in three sites: a lowland site on predominantly granitic parent materials, an upland site on granitic parent materials and an upland site on dolomitic parent materials.

\section{Methods}

Study site

Samples were collected at the Alexandra Fiord lowland on Ellesmere Island, Nunavut, Canada, $78^{\circ} 53^{\prime} \mathrm{N}, 75^{\circ} 55^{\prime} \mathrm{W}$. The mesic Lowland Granitic (LG) site was near sea level $(30 \mathrm{~m})$ and enclosed by $500-700 \mathrm{~m}$ plateaus to the east and west, Twin Glacier to the south, and the waters of Alexandra Fiord to the north. The growing season climate at the lowland site is relatively warm due to frequently clear skies, relatively warm air masses from the west and south (Labine, 1994), and reflection of sunlight from the glaciers and sea ice into the lowland (Freedman et al., 1994). The soils are mainly regosolic cryosols (Muc et al., 1994a) composed of granitic parent materials (Sterenberg and Stone, 1994). The lowland site has been classified as a dwarf shrub-cushion plant community and is dominated by Cassiope tetragona, Dryas integrifolia and S. arctica, along with Vaccinium uliginosum, Saxifraga oppositifolia and Luzula nivalis (Muc et al., 1994b). The upland sites were located on top of the western plateau at $500 \mathrm{~m}$. These sites were xeric with sparse vegetation and exhibit polar desert and semi-desert conditions. Vascular plant diversity was approximately $40 \%$ lower than the lowland site (Batten and Svoboda, 1994). The two upland sites were distinguished by soil type: the Upland Granitic (UG) site occurred on granitic parent materials similar to the lowland site, and the Upland Dolomitic (UD) site developed from dolomitic parent materials, which were characterized by high concentrations of calcium magnesium carbonate $\left(\mathrm{CaMg}\left(\mathrm{CO}_{3}\right)_{2}\right)$, high $\mathrm{pH}$, and low organic matter deposition. The UG site was dominated by $S$. arctica and $S$. oppositifolia, with $C$. tetragona and $D$. integrifolia as minor components. The UD site was dominated by $D$. integrifolia, $S$. arctica and $S$. oppositifolia; C. tetragona was absent at this site (Batten and Svoboda, 1994).

\section{Experimental warming}

To experimentally increase temperature, open-top chambers (OTCs), which covered $0.8 \mathrm{~m}^{2}$ and were $0.3 \mathrm{~m}$ high, were used to passively warm plots at each of the sites. OTCs increase air temperatures by $1-4{ }^{\circ} \mathrm{C}$ (Marion et al., 1997), although their effect on soil temperature is more variable, with increases and decreases being observed (Hollister et al., 2006). OTCs were installed at the LG site in 1995 and at the two upland sites in 1993 (Stenström et al., 1997).

\section{Field collection}

Two specimens of $S$. arctica were harvested from each of three OTC plots at each site in August 2000. Two plants that were found between 0.5 and $1.5 \mathrm{~m}$ from each OTC were harvested as ambient controls. Plants and surrounding soil were kept in Ziploc bags $(18 \times 20 \mathrm{~cm})$ in a permafrost cooler at approx. $-1{ }^{\circ} \mathrm{C}$ until transported to the laboratory.

For soil analysis, two $300 \mathrm{~g}$ samples of soil were collected in August 2001 within $1 \mathrm{~m}$ of the harvested ambient plants. Soils were dried and sieved $(2 \mathrm{~mm})$ to remove rocks and course debris from the samples. One hundred grams from each of the two replicates was mixed and sent to the Ministry of Forests Analytical Laboratory (Victoria, British Columbia, Canada) for the following analyses: $\mathrm{pH}$ in water, total $\mathrm{C}$ and $\mathrm{N}$ using combustion elemental analysis, cation exchange capacity and exchangeable cations using $0.1 \mathrm{~N}$ barium chloride extraction, available $\mathrm{NH}_{4}-\mathrm{N}$ and $\mathrm{NO}_{3}-\mathrm{N}$ extracted with $2 \mathrm{~N} \mathrm{KCl}$, and available P using the Mehlich III protocol.

\section{Sampling from roots}

Plant roots were kept cold during transport and stored at $4{ }^{\circ} \mathrm{C}$ prior to sampling. Roots were immersed in water for up to $24 \mathrm{~h}$ at $4{ }^{\circ} \mathrm{C}$ prior to washing to loosen adhering materials. The root systems were then vigorously washed with running tap water and collected in a $0.5 \mathrm{~mm}$ sieve. Roots were cut into $2 \mathrm{~cm}$ sections then immersed in sterile 
distilled water on a numbered grid. The root segment that traversed or was closest to a randomly selected grid point was selected. One root tip was excised from each segment, rinsed with sterile distilled water, placed in a $1.5 \mathrm{ml}$ microcentrifuge tube and then frozen at $-40{ }^{\circ} \mathrm{C}$ until DNA was extracted. Thirty root segments were randomly selected from each plant. Leaf tissue was also sampled to confirm that plant DNA would not amplify with the chosen primers.

DNA extraction and ITS-terminal restriction fragment length polymorphism analysis

DNA was extracted from root tips using a CTAB protocol (Gardes and Bruns, 1996) which was modified by excluding the freeze-thaw cycle and by including an additional phenol/chloroform-isoamyl alcohol (1:1) purification step (Lee and Taylor, 1990). The pellet was re-suspended in $50 \mu \mathrm{l}$ of TE-8 buffer. Plant tissues were extracted with the same protocol except the extra phenol/chloroform-isoamyl alcohol purification step was not included, and pellets were re-suspended in $100 \mu \mathrm{l}$ of TE-8. All extractions were stored at $-20^{\circ} \mathrm{C}$.

The primer pair ITS1 and ITS4 (White et al., 1990) was used to amplify the nrDNA internal transcribed spacer region from root DNA extracts. The ITS1 forward primer was labeled with Cy5 dye and the ITS4 reverse primer was labeled with Cy5.5 dye to allow detection by an OpenGene fragment analyzer (Bayer Healthcare, Tarrytown, NY, USA). PCR cocktails consisted of $0.2 \mathrm{mM}$ dNTPs, $0.5 \mu \mathrm{M}$ primers, $2.5 \mathrm{mM} \mathrm{MgCl}_{2}, 1 / 10$ th volume of $10 \times$ PCR buffer and $0.72 \mathrm{U}$ of Platinum Taq DNA polymerase (Invitrogen, Burlington, Canada) in a final volume of $19 \mu \mathrm{l}$ to which was added $1 \mu \mathrm{l}$ of a 1:10 dilution of the DNA extract. Samples which did not amplify successfully at a 1:10 dilution were redone using $1 \mu \mathrm{l}$ of undiluted DNA extract. The following program was used for PCR on a PTC-100 thermocycler (MJ Research): $94{ }^{\circ} \mathrm{C}(4 \mathrm{~min}) ; 48{ }^{\circ} \mathrm{C}(1 \mathrm{~min})$; $72{ }^{\circ} \mathrm{C}(2 \mathrm{~min}) ;\left(94{ }^{\circ} \mathrm{C}(30 \mathrm{~s}) ; 48^{\circ} \mathrm{C}(30 \mathrm{~s}) ; 72^{\circ} \mathrm{C}(1 \mathrm{~min}\right.$ $30 \mathrm{~s}) \times 34$ cycles $) ; 72{ }^{\circ} \mathrm{C}(6 \mathrm{~min} 30 \mathrm{~s})$. Samples were run on a $0.7 \%$ agarose gel to confirm amplification.

Digestions using AluI or HinfI (Invitrogen) and $6 \mu \mathrm{l}$ of the PCR product were done in $10 \mu \mathrm{l}$ reactions following the manufacturer's recommendations and incubated at $37^{\circ} \mathrm{C}$ for at least $3 \mathrm{~h}$. One microliter of the digested samples was mixed with $1.65 \mu \mathrm{l}$ of loading dye mixture that contained formamide and two sets of internal markers at 101, 200 and $351 \mathrm{bp}$; one set labeled with Cy 5.0, the other with Cy 5.5. The samples containing the loading dye mixture were denatured at $80^{\circ} \mathrm{C}$ for 2 min then quenched on ice. Two microliters were then loaded onto a $6 \%$ polyacrylamide gel with the laser power set at $50 \%$, temperature at $53^{\circ} \mathrm{C}$, and current at $1250 \mathrm{~V}$ and run for $60 \mathrm{~min}$ on an OpenGene System Long Tower Sequencer (Bayer International). Terminal fragments that exceeded a threshold value based upon the size of the marker peaks were determined using GeneObjects 3.1 fragment analysis software (Bayer Healthcare, Tarrytown, NY, USA) for each primerenzyme combination (that is, ITS1-AluI, ITS1-HinfI, ITS4-AluI and ITS4-HinfI).

\section{Data analysis}

Peaks were binned to identify genotypes, and then genotype frequency was tabulated for each enzymeprimer combination. Genotype density per root tip, richness and evenness were calculated separately for each of the four enzyme-primer combinations then averaged to provide an estimate of each parameter. Genotype frequency tables from each of the four enzyme-primer combinations were combined for use in perMANOVA, ordination and twoway cluster analyses.

Genotype density was standardized by dividing by the total number of root tips sampled per plot because the number of root tips from each plant specimen varied. Standardization assumed that genotypes were absent from samples that were unsuccessful after at least two separate PCR amplifications at different dilutions. A two-way analysis of variance (ANOVA) was run using Statistica, vers. 6.1 (StatSoft, Tulsa, OK, USA) to investigate the effects of site and treatment on genotype density. To determine if density was correlated with increased biomass, a two-way ANOVA was run using a measure of amplification efficiency (number of root tips amplified/number of root tips attempted).

Genotype richness was measured as the number of unique genotypes per plot. Hurlbert's probability of interspecific encounter index, as implemented in EcoSim 7.72 (Gotelli and Entsminger, 2006), was used to assess evenness. Because genotype density varied significantly between sites and treatments, genotype richness and evenness were standardized using individual-based rarefaction as implemented in the program EcoSim v. 7.72 (Gotelli and Entsminger, 2006). Rarefaction ensured that differences in genotype richness or evenness were not artifacts caused by differences in sampling intensity. Two-way ANOVA was performed for both richness and evenness.

Nonmetric multidimensional scaling using PCORD, version 5.03 (McCune and Mefford, 1999) was used to examine the distribution of plots in genotype space. Canonical Correspondence Analysis (CCA) (McCune and Mefford, 1999) was used to examine whether soil properties (that is, $\mathrm{pH}$, CEC, available $\mathrm{NH}_{4}$, available $\mathrm{NO}_{3}$, available $\mathrm{P}, \mathrm{C} / \mathrm{N}$ ratio and exchangeable cations) explained differences in genotype frequency and composition among sites. Soil properties were transformed by $\log _{10}$ except for $\mathrm{pH}$ and $\mathrm{C} / \mathrm{N}$ ratio. A Monte Carlo test was used to test linear relationships between the genotype frequency and soil properties. A two-way, nested ANOVA was used to test if warming affected soil properties (Table 1): (p.p.m. for $\mathrm{P}$ and available N), 
Table 1 Mean and standard error of soil analysis variables

\begin{tabular}{|c|c|c|c|c|c|c|}
\hline \multirow{2}{*}{$\begin{array}{l}\text { Site } \\
\text { Treatment }\end{array}$} & \multicolumn{2}{|c|}{ Lowland Granitic } & \multicolumn{2}{|c|}{ Upland Dolomitic } & \multicolumn{2}{|c|}{ Upland Granitic } \\
\hline & Ambient & OTC & Ambient & OTC & Ambient & OTC \\
\hline CEC (Ba) $\left(\mathrm{cmol}+\mathrm{kg}^{-1}\right)$ & $6.767 \pm 0.973$ & $5.623 \pm 0.936$ & $11.097 \pm 1.268$ & $8.953 \pm 0.768$ & $7.747 \pm 0.644$ & $8.260 \pm 0.626$ \\
\hline Exch Ca $\left(\mathrm{cmol}+\mathrm{kg}^{-1}\right)$ & $4.115 \pm 0.651$ & $3.419 \pm 0.643$ & $7.587 \pm 0.841$ & $5.841 \pm 0.523$ & $4.052 \pm 0.378$ & $4.170 \pm 0.207$ \\
\hline Exch Fe $\left(\mathrm{cmol}+\mathrm{kg}^{-1}\right)$ & $0.006+0.005$ & $0.002+0.001$ & $<0.001$ & $<0.001$ & $0.002+0.001$ & $0.002+0.001$ \\
\hline Exch Mg $\left(\mathrm{cmol}+\mathrm{kg}^{-1}\right)$ & $2.298 \pm 0.288$ & $1.926 \pm 0.274$ & $3.408 \pm 0.440$ & $3.008 \pm 0.290$ & $3.441 \pm 0.367$ & $3.892 \pm 0.426$ \\
\hline $\mathrm{pH}\left(\mathrm{H}_{2} \mathrm{O}\right)$ & $5.553 \pm 0.199$ & $5.480 \pm 0.046$ & $8.037 \pm 0.099$ & $8.173 \pm 0.007$ & $5.867 \pm 0.428$ & $6.157 \pm 0.055$ \\
\hline Total C\% & $0.947 \pm 0.309$ & $0.817 \pm 0.162$ & $5.627 \pm 1.007$ & $5.883 \pm 0.963$ & $0.870 \pm 0.475$ & $0.543 \pm 0.082$ \\
\hline Total N \% & $0.064 \pm 0.019$ & $0.054 \pm 0.011$ & $0.058 \pm 0.006$ & $0.047 \pm 0.003$ & $0.074 \pm 0.041$ & $0.044 \pm 0.006$ \\
\hline $\mathrm{NO}_{3}^{-} \mathrm{N}$ (p.p.m.) & $52.443 \pm 7.806$ & $40.550 \pm 5.034$ & $10.203 \pm 1.760$ & $10.363 \pm 0.214$ & $33.557 \pm 17.146$ & $28.637 \pm 2.844$ \\
\hline $\mathrm{NH}_{4}^{+} \mathrm{N}$ (p.p.m.) & $1.483 \pm 0.690$ & $1.343 \pm 0.216$ & $0.710 \pm 0.064$ & $0.467 \pm 0.033$ & $6.210 \pm 2.394$ & $2.997 \pm 0.066$ \\
\hline Avail P (p.p.m.) & $3.767 \pm 0.442$ & $3.757 \pm 0.436$ & $0.483 \pm 0.242$ & $0.003 \pm 0.003$ & $1.977 \pm 0.502$ & $1.723 \pm 0.243$ \\
\hline
\end{tabular}

concentration (exchangeable cations and CEC), or ratio $(\mathrm{C} / \mathrm{N}, \mathrm{pH})$, which could explain some of the variation due to site or treatment.

PerMANOVA performs distance-based multivariate ANOVA. The implementation of perMANOVA in PC-ORD, version 5.03 (McCune and Mefford, 1999) using the Relative Sorensen Index was used to explore whether site or treatment (warming) was a statistically significant factor explaining differences in genotype frequency and composition. The Relative Sorensen Index standardizes the data by sample units, thereby shifting the emphasis from absolute frequency of genotypes to relative proportions within sample units (McCune and Mefford, 1999).

Two-way cluster analysis, as implemented in PCORD, version 5.03 (McCune and Mefford, 1999) using the Relative Sorensen Index and the flexible $\beta$ $(\beta=-0.25)$ method for linking groups, permitted examination of the distribution of the major genotypes between plots.

Genotype diversity was also investigated by examining genotype rank abundance curves, which were generated by taking the natural log of genotype abundance (measured as number of occurrences of a genotype relative to the total number of individual genotypes observed) and plotting it against the genotype abundance rank. Niche apportionment analyses were conducted using PowerNiche (Drozd and Novotny, 1999), an Excel-based macro which helps determine if rank abundance curves fit niche apportionment models based on the works of Tokeshi, Sugihara, and MacArthur (see Magurran, 2004). The selection and division exponents were varied for each test of the power model with 250 replications. Different models were tested by changing the selection $(=k)$ and division exponent $(=m)$, which is indicative of which niche apportionment model is chosen. The following models were tested: the broken stick model $(k=1, m=1)$, the random fraction model $(k=0, m=1)$, the power fraction model $(0<k<1, \quad m=1)$, and Sugihara's sequential breakage model $(k=0, m=0: 25: 0: 75)$ (Drozd and Novotny, 1999).

\section{Results}

Our experimental design utilized three sites with three randomly placed replicates of OTC and ambient control treatments within each site. For each site/treatment, we sampled approximately 30 root tips (Mean $30.69 \pm 5.61$ s.d.) from each of two plants. To alleviate concerns that root tips from individual plant replicates were not independent estimates of genotype density or richness (that is, root tips from the same plant were more similar), we ran preliminary two-way, nested ANOVA with plant specimen nested within replicates of the treatment (warmed plots or control). These preliminary analyses confirmed that plant replicate was not a significant factor $(P=0.551-0.876)$. We conclude that root tip samples from a single plant are no more similar than the pooled sample from both plants, which is consistent with a model of colonization where most colonization of flushing roots is via soilborne inoculum rather than from existing inoculum on the roots. On this basis, we felt justified in eliminating plant specimen replicates from the final analyses, and therefore we did not violate the assumption of independence because only the two independent variables, site and treatment, were used in our final ANOVA model.

The main effect of 5-7 years of warming was to increase genotype density (number of different genotypes per root tip) on roots. Density increased significantly in warmed plots at all sites $(\mathrm{F}(1,12)=15.003, P=0.00221)$. Density also varied significantly among sites, being significantly lower for the UD site compared to the other two sites $(\mathrm{F}(2,12)=29.396, P=0.00002)$ (Figure 1). There was no significant interaction between site and treatment $(\mathrm{F}(2,12)=0.73268, P=0.50093)$. Amplification efficiency did not vary significantly by site $(\mathrm{F}(2,30)=0.13547, \quad P=0.87384)$ or by treatment $(\mathrm{F}(1,30)=2.7909, P=0.10520)$ at the $95 \%$ confidence level, but this will be addressed further in the Discussion section.

Genotype richness also varied significantly among sites $(\mathrm{F}(2,12)=4.3367, P=0.03825)$, with the lowest 


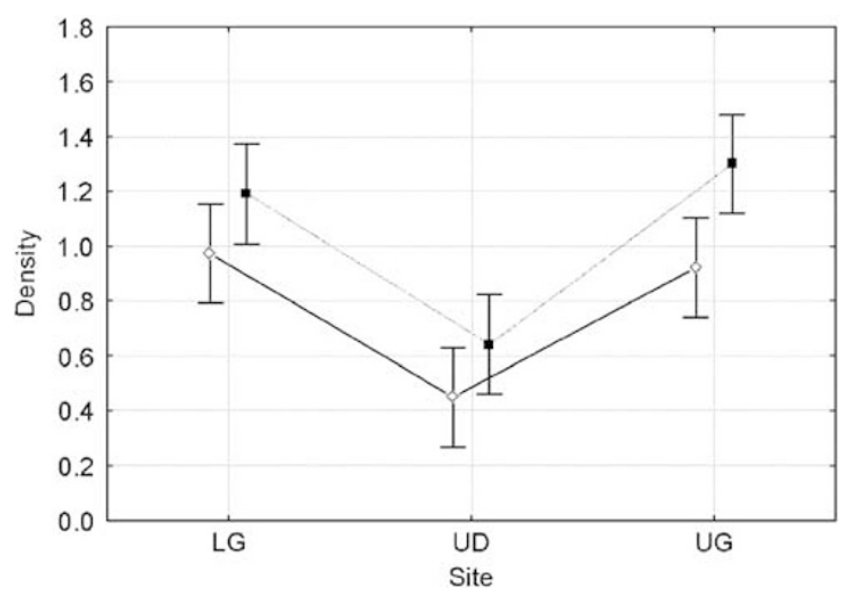

Figure 1 The effect of site and treatment on genotype density (number of genotypes per root tip). Error bars indicate 95\% confidence intervals. Open diamonds indicate ambient control plots, filled squares indicate OTC warmed plots. OTC, open-top chamber.

richness observed on the UD site and the highest on the LG site (Figure 2), but there was no effect of treatment on richness $(\mathrm{F}(1,12)=0.05493$, $P=0.81865)$. There was no significant interaction between site and treatment $(\mathrm{F}(2,12)=0.09930$, $P=0.90621)$. Evenness did not vary significantly by site or treatment.

Preliminary analysis using nonmetric multidimensional scaling (data not shown) of plots in genotype space showed that communities were strongly structured by site but not by treatment. Site and soil characteristics (Table 1) were the main factors differentiating communities according to the results from CCA (Figure 3). The dimensions for the CCA analysis were 18 plots and 360 genotypes for the main matrix and 18 plots and 8 variables for the environmental factors matrix. For the final CCA, Ca was excluded because of its high correlation with CEC $(r=0.94)$. Three axes were interpreted; the first axis $\left(r^{2}=-0.694\right)$ explained $11.3 \%$ of the variance, the second $\left(r^{2}=-0.705\right) \quad 9.9 \%$ and the third $\left(r^{2}=0.121\right) 7.3 \%$. Results from the Monte Carlo test indicated that eigenvalues $(P=0.002)$ and speciesenvironment correlations $(P=0.01)$ were significantly higher than expected by chance. The rootassociated fungal communities from the LG and UG sites were more similar to each other than to the UD site, reflecting the similarity in soil properties. Both granitic sites were more strongly associated with available $\mathrm{P}$, but the LG site was more strongly associated with $\mathrm{Fe}$ and nitrate $\mathrm{N}$ availability while the UG site was more strongly associated with ammonium N. The upland sites were more strongly associated with $\mathrm{Mg}$ availability. The UD site was strongly associated with $\mathrm{pH}, \mathrm{C} / \mathrm{N}$ ratio and $\mathrm{CEC}$, as would be expected on a site with dolomite as parent material (Figure 3). Results from the two-way nested ANOVA on the different soil properties confirmed

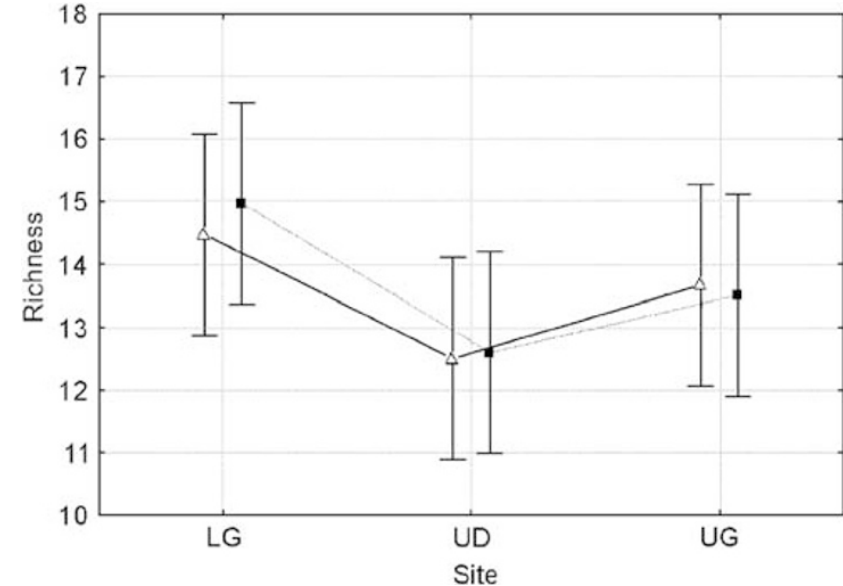

Figure 2 The effect of site and treatment on genotype richness (number of genotypes per plot). Richness was standardized by individual-based rarefaction to compensate for differences in density between samples. Error bars indicate 95\% confidence intervals. Open triangles indicate ambient control plots, filled squares indicate OTC warmed plots. OTC, open-top chamber.

that soil properties differed significantly among sites, but did not change due to warming.

PerMANOVA analysis of community composition based upon the Relative Sorensen index supported the CCA results. Genotype composition differed significantly among sites $(\mathrm{F}(2,12)=5.0301$, $P=0.0002)$, but not treatments $(\mathrm{F}(1,12)=0.94759$, $P=0.4644)$.

Two-way cluster analysis (Figure 4) produced much the same groupings as the CCA analysis, with sites clustering together but treatments not consistently grouped within site clusters. With regard to the distribution of genotypes among the sites, cluster $268 \mathrm{~h} 55$ to $286 \mathrm{~h} 5$ contained genotypes that were widely distributed among all sites; cluster $341 \mathrm{~h} 55$ to $173 \mathrm{a} 55$ genotypes were also widely distributed, but had a greater frequency in the upland sites; cluster $265 \mathrm{~h} 55$ to $115 \mathrm{a} 5$ represents genotypes that are largely restricted to LG and UG sites but with higher frequency on the UG site; cluster $292 \mathrm{~h} 5$ to $82 \mathrm{~h} 5$ represents genotypes that predominate in the LG site, although they are found to a lesser extent in the UG site; cluster $274 \mathrm{~h} 5$ to $331 \mathrm{~h} 5$ contains genotypes that are more strongly represented in the UG samples, but also occur sporadically in other samples. Members of cluster 215 h55 to 171 a 5 are sporadically distributed among plots without a clear pattern. When comparing the genotype distribution between control and warmed plots, most of the dominant genotypes within each site were present in both treatments. Some genotypes may be responding to warming, but it was difficult to detect consistent genotype responses, which is consistent with the results of the statistical analyses.

Niche apportionment analyses indicated that the root-associated fungal communities we studied exhibited a log normal distribution. Analyses with 


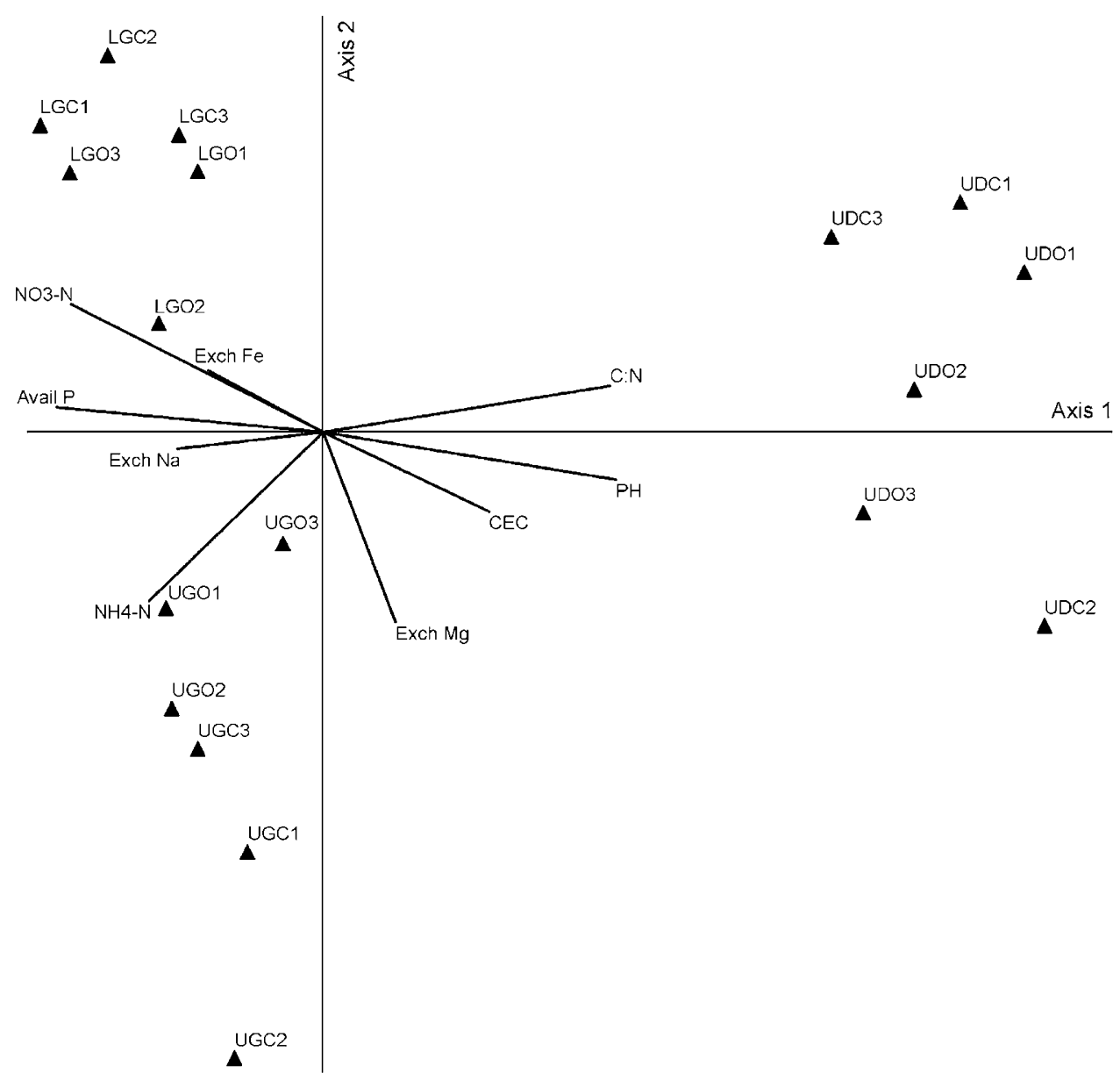

Figure 3 CCA biplot of warming treatments and site with soil properties. Coding is as follows: the first two characters represent site, LG, UD, UG; the third character signifies the treatment: $\mathrm{C}$ (ambient control) or O (OTC warmed); and the fourth character indicates the replicate number. Soil properties are plotted as vectors radiating from the center, and were used to assess the relationship between genotype and soil properties. CCA, Canonical Correspondence Analysis; LG, Lowland Granitic; OTC, open-top chamber; UD, Upland Dolomitic; UG, Upland Granitic.

PowerNiche based upon Tokeshi's niche apportionment models indicated that relative abundance curves of all four primer-enzyme combinations fit the power fraction model for the UG site, three of the four primer-enzyme combinations for the LG site also fit the power fraction model (the ITS4-AluI abundance curve fit the broken stick model), and all four primer-enzyme combinations fit the broken stick model for the UD site.

\section{Discussion}

Two hypotheses could explain the observed increase in genotype density: (1) there was a general increase in fungal biomass in roots resulting in higher amplification efficiency and hence increased likelihood of detecting genotypes or (2) that we are observing the initial stages of a replacement process and are detecting both indigenous and colonizing fungi on roots. Since we did not directly measure biomass, we analyzed amplification efficiency with the expectation that a general increase in fungal biomass on root tips would result in higher efficiency of amplification, whereas replacement would not. Although differences in amplification efficiency between ambient and warmed plots were not significant at the standardly accepted 95\% confidence level, there was an increase in amplification efficiency with warming at all sites and the probability $(P=0.10520)$ was sufficiently high that hypothesis 1 remains the most parsimonious explanation for the increase in density; this hypothesis will be tested in future studies. This hypothesis is consistent with the lack of significant change in genotype richness or evenness, and examination of genotype distributions, which suggested that the increased density of genotypes on individual roots in warmed plots was due to colonization by existing genotypes rather than an influx of novel genotypes. Chapin et al. (1995) found significant increases in plant biomass after 9 years of experimental warming in the low arctic, and recent evidence indicates that large increases in belowground biomass are accompanying these changes (Hill, 2006). Previous studies have shown mycorrhizal biomass to increase 


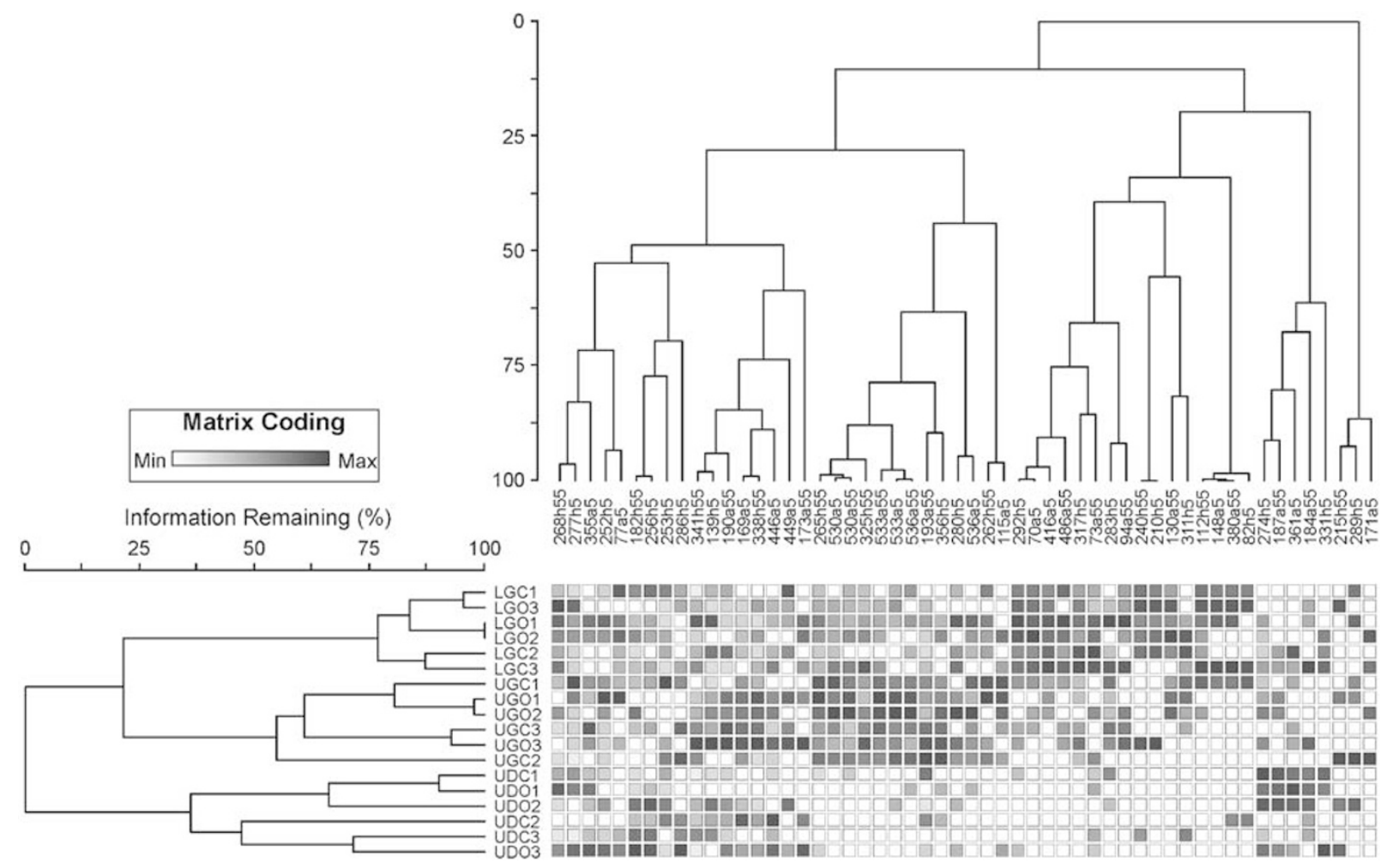

Figure 4 Two-way cluster analysis of fungal genotypes. Labels in the horizontal dendrogram are coded as follows: the first two characters represent site, LG, UD, UG; the third character signifies the treatment: C (ambient control) or O (OTC warmed); and the fourth character indicates the replicate number. Labels in the vertical dendrogram indicate genotype fragment size (first 2-3 digits), restriction endonuclease $(\mathrm{h}=$ HinfI; $\mathrm{a}=$ AluI), and Cy dye (Cy5 = forward primer; Cy55= reverse primer). LG, lowland granitic; OTC, open-top chamber; UD, Upland Dolomitic; UG, Upland Granitic.

in response to warming (Clemmensen et al., 2006); the increase in genotype density observed in our study is consistent with these observations.

The lack of a change in richness or evenness suggests that the entire root-associated fungal community benefited from the warmer temperatures and increased carbon allocation belowground. This finding is contrary to a previous study examining the effects of warming on ectomycorrhizal fungal communities of Douglas-fir seedlings. Rygiewicz et al. (2000) found an increase in the number of different mycorrhizal fungi on seedlings grown in controlled environment chambers with elevated temperatures compared to those grown in chambers with ambient temperatures. Differences in results between our study could be due to the following: (1) differences in how the hosts react to warming; (2) the age of the plant, as seedlings were used for their study while we sampled mature shrubs and (3) greater availability of fungal inoculum, which may be more widely dispersed at lower latitudes, providing greater opportunity for migration of new genotypes. We also did not find an initial decrease in diversity due to warming as some studies have found for plant diversity (Chapin et al., 1995; Hollister et al., 2005; Walker et al., 2006), although Jónsdóttir et al. (2005) noted that there was no change in species richness of plant communities in
Iceland and suggest that initial conditions may dictate responses to warming.

Site and soil characteristics are important determinants of bacterial community structure at small scales (for example, Ritz et al., 2004), but we expected root-associated fungal communities to be more strongly buffered by host interactions. In this study, we found that genotypes on a single host plant species in this restricted geographical area were strongly associated with specific sites along altitudinal and soil physicochemical gradients. Reasons for the low richness and density at the dolomitic site include a high $\mathrm{C} / \mathrm{N}$ ratio, which is not conducive to the breakdown of organic matter, and low levels of $\mathrm{NH}_{4}, \mathrm{NO}_{3}$ and $\mathrm{P}$, suggesting that both nitrogen and phosphorus may be limiting factors at the UD site. Although not statistically significant, $P$ levels dropped to negligible levels in the warmed plots on the dolomitic site. The lack of available P could explain the paucity of plants and mycorrhizal fungi present at this site. However, some ectomycorrhizal fungi can solubilize calcium phosphate (Martin et al., 2000); fungi that can fulfill this role may have a competitive advantage, which could be a factor in dictating the community composition of this site. The UG and LG sites were more similar in community composition, although the more xeric and harsh UG site had lower genotype richness. 
Relative abundance distributions of species in Arctic plant communities have been reported to conform to a geometric series model (McKane et al., 2002), which is commonly associated with speciespoor, harsh environments or species found in early succession (Magurran, 2004); therefore, we hypothesized that we would find similar distribution patterns indicating a species-poor, root-associated fungal community. This was not the case, as shown by genotype richness and niche apportionment models. Our arctic system had 25-35 genotypes for the two granitic sites (LG and UG), which is comparable to other studies using terminal restriction fragment length polymorphism analysis in temperate forests, where 19-35 genotypes were found in an oak shrub community (Klamer et al., 2002) and 26 genotypes in a 60-year-old pine plantation (Dickie et al., 2002). Our root-associated fungal communities exhibited a log-normal distribution, which is usually associated with more diverse ecosystems such as temperate and tropical forests (McKane et al., 2002), and typical of ectomycorrhizal fungal communities on temperate trees with more extensive root systems (Horton and Bruns, 2001). Analyses with PowerNiche based upon Tokeshi's niche apportionment models indicated that relative abundance curves for the LG and UG sites more closely fit the power fraction model while the broken stick model fit better for the UD site. In the power fraction model, abundant species are more likely to successfully invade or inhabit niche space (Tokeshi, 1999) or in this case colonize a segment of root. Once a root tip is occupied, other fungi may be challenged to outcompete the existing fungus. The genotypes that increased in density due to warming were generally dominant genotypes, which is consistent with the power fraction model. In the broken stick model, resources are evenly divided among species (Magurran, 2004). This model may have been better applied to the UD site because both the plant and fungal diversity is limited and dominated by fungi that can tolerate the low nutrient status and environmental extremes of this site. Those fungi that tolerate these constraints appear to allocate the limited resources more equitably.

Our findings suggest that the root-associated fungal community at these tundra sites were quite resilient to warming, as evidenced by the lack of change in genotype richness or evenness (Kårén and Nylund, 1997; Rygiewicz et al., 2000). Over longer time periods, it would be interesting to know if sites with higher richness, such as the LG and UG sites, are more resilient than the UD site. Also, it would be valuable to extend these results using DNA sequencing or genomic approaches, as genotype richness may have been partially masked by the lower taxonomic resolution of the terminal restriction fragment length polymorphism technique. How will global warming affect the root-associated fungal community on $S$. arctica? Commensurate with an increase in carbon allocation belowground, we predict an increase in colonization by root-associated fungi. Significant changes in community composition are likely to be slower, and to be highly localized due to the strong effect of site and environment upon community structure. However, we only examined a single host. If the hypothesis that plant diversity will increase with long-term warming is correct (Chapin et al., 1995; Arft et al., 1999; Walker et al., 2006), then this may alter the root-associated fungal community by providing new hosts and increase the potential for facilitation of multi-host fungi.

\section{Acknowledgements}

We thank Cecilia Alström-Rapaport for statistical advice; Clive Owens of the British Columbia Ministry of Forests Analytical Research Laboratory for analyzing the soil samples; Lito Arocena and Yuriko Yano for assistance with soil data interpretation; Sara Jamieson for help in preparing samples; Linda Rehaume for laboratory assistance; and Ed Kraay for technical support. This research was supported by grants from the Natural Sciences \& Engineering Research Council of Canada to KNE and GHRH and by a grant from the ArcticNet NCE to GHRH. We are grateful for the logistical support from the Polar Continental Shelf Project and the Royal Canadian Mounted Police.

\section{References}

ACIA (2005). Arctic Climate Impact AssessmentScientific Report. Cambridge University Press: Cambridge, UK.

Arft AM, Walker MD, Gurevitch J, Alatalo JM, Bret-Harte MS, Dale M et al. (1999). Responses of tundra plants to experimental warming: meta-analysis of the international tundra experiment. Ecol Monogr 69: 491-511.

Batten DS, Svoboda J. (1994). Plant communities on the uplands in the vicinity of the Alexandra Fiord lowland. In: Svoboda J, Freedman B (eds). Ecology of a Polar Oasis: Alexandra Fiord, Ellesmere Island, Canada. Captus University Publications: Toronto, pp 97-110.

Bledsoe C, Klein P, Bliss LC. (1990). A survey of mycorrhizal plants on Truelove Lowland, Devon Island, N.W.T., Canada. Can J Bot 68: 1848-1856.

Cázares E, Trappe J, Jumpponen A. (2005). Mycorrhizaplant colonization patterns on a subalpine glacier forefront as a model system of primary succession. Mycorrhiza 15: 405-416.

Chapin III FS, Shaver GR, Giblin AE, Nadelhoffer KJ, Laundre JA. (1995). Responses of arctic tundra to experimental and observed changes in climate. Ecology 76: 694-711.

Clemmensen K, Michelsen A. (2006). Integrated long-term responses of an arctic-alpine willow and associated ectomycorrhizal fungi to an altered environment. Can J Bot 84: 831-843.

Clemmensen K, Michelsen A, Jonasson S, Shaver G. (2006). Increased ectomycorrhizal fungal abundance 
after long-term fertilization and warming of two arctic tundra ecosystems. New Phytol 171: 391-404.

Cornelissen JHC, Callaghan TV, Alatalo JM, Michelsen A, Graglia E, Hartley AE et al. (2001). Global change and arctic ecosystems: is lichen decline a function of increases in vascular plant biomass? J Ecol 89: 984-994.

Dickie I, Xu B, Koide R. (2002). Vertical niche differentiation of ectomycorrhizal hyphae in soil as shown by T-RFLP analysis. New Phytol 156: 527-535.

Drozd P, Novotny V. (1999). PowerNiche: Niche division models for community analysis http://www.entu. cas.cz/png/PowerNiche.

Fitter A, Heinemeyer A, Husband R, Olsen E, Ridgway K, Staddon P. (2004). Global environmental change and the biology of arbuscular mycorrhizas: gaps and challenges. Can J Bot 82: 1133-1139.

Freedman B, Svoboda J, Henry GHR. (1994). Alexandra Fiord-an ecological oasis in the polar desert. In: Svoboda J, Freedman B (eds). Ecology of a Polar Oasis: Alexandra Fiord, Ellesmere Island, Canada. Captus University Publications: Toronto, pp 1-9.

Gardes M, Bruns TD. (1996). Community structure of ectomycorrhizal fungi in a Pinus muricata forest: above- and below-ground views. Can J Bot 74: 1572-1583.

Gardes M, Dahlberg A. (1996). Mycorrhizal diversity in arctic and alpine tundra: an open question. New Phytol 133: 147-157.

Gotelli NJ, Entsminger GL. (2006). EcoSim null models software for ecology, vers. 7, http://www.garyentsminger. com/ecosim.

Heinemeyer A, Fitter AH. (2004). Impact of temperature on the arbuscular mycorrhizal (AM) symbiosis: growth responses of the host plant and its AM fungal partner. $J$ Exp Bot 55: 525-534.

Henry GHR. (2002). Effects of long-term experimental warming on high arctic tundra ecosystems. Integer Compare Biol 42: 1243.

Henry GHR, Molau U. (1997). Tundra plants and climate change: The international tundra experiment (ITEX). Global Change Biol 3: 1-9.

Hill G. (2006). Responses of high arctic sedge meadows to climate warming at Alexandra Fiord, Ellesmere Island, since 1980. MSc thesis, University of British Columbia, Vancouver, Canada, 71pp.

Hollister RD, Webber PJ, Nelson FE, Tweedie CE. (2006). Soil thaw and temperature response to air warming varies by plant community: results from an open-top chamber experiment in northern Alaska. Arct Antarct Alp Res 38: 206-215.

Hollister RD, Webber PJ, Tweedie CE. (2005). The response of Alaskan arctic tundra to experimental warming: differences between short- and long-term responses. Global Change Biol 11: 525-536.

Horton TR, Bruns TD. (2001). The molecular revolution in ectomycorrhizal ecology: peeking into the black-box. Mol ECol 10: 1855-1871.

Jónsdóttir IS, Magnusson B, Gudmundsson J, Elmarsdottir A, Hjartarson H. (2005). Variable sensitivity of plant communities in Iceland to experimental warming. Global Change Biol 11: 553-563.

Jumpponen A. (1999). Spatial distribution of discrete RAPD phenotypes of a root endophytic fungus, Phialocephala fortinii, at a primary successional site on a glacier forefront. New Phytol 141: $333-344$
Jumpponen A. (2001). Dark septate endophytes-are they mycorrhizal? Mycorrhiza 11: 207-211.

Kårén O, Nylund JE. (1997). Effects of ammonium sulphate on the community structure and biomass of ectomycorrhizal fungi in a Norway spruce stand in southwestern Sweden. Can I Bot 75: 1628-1642.

Klamer M, Roberts MS, Levine LH, Drake BG, Garland JL. (2002). Influence of elevated $\mathrm{CO}_{2}$ on the fungal community in a coastal scrub oak forest soil investigated with terminal-restriction fragment length polymorphism analysis. Appl Environ Microbiol 68: 4370-4376.

Labine C. (1994). Meteorology and climatology of the Alexandra Fiord lowland. In: Svoboda J, Freedman B (eds). Ecology of a Polar Oasis: Alexandra Fiord, Ellesmere Island, Canada. Captus University Publications: Toronto. pp 23-39.

Lee S, Taylor J. (1990). Isolation of DNA from fungal mycelia and single spores. In: Innis MA, Gelfand DH, Sninsky JJ, White TJ (eds). PCR Protocols: a Guide to Methods and Applications. Academic Press: NY, USA, pp 282-287.

Magurran AE. (2004). Measuring Biological Diversity. Blackwell Science: Oxford, UK.

Marion GM, Henry GHR, Freckman DW, Johnstone J, Jones $\mathrm{G}$, Jones $\mathrm{MH}$ et al. (1997). Open-top designs for manipulating field temperature in high-latitude ecosystems. Global Change Biol 3: 20-32.

Martin F, Perotto S, Bonfante P. (2000). Mycorrhizal fungi: a fungal community at the interface between soil and roots. In: Pinton R, Varanini Z, Nannipieri P (eds). The Rhizosphere. Biochemistry and Organic Substances at the Soil-Plant Interface. Marcel Dekker Inc: New York, USA, pp 263-296.

McCune B, Mefford MJ. (1999). PC-ORD-Multivariate Analysis of Ecological Data, Vers. 5.0. MjM Software, Gleneden Beach, OR, USA.

McKane RB, Johnson LC, Shaver GR, Nadelhoffer KJ, Rastetter EB, Fry B et al. (2002). Resource-based niches provide a basis for plant species diversity and dominance in arctic tundra. Nature 415: 68-71.

Muc M, Freedman B, Svoboda J. (1994a). Soils of an extensively vegetated polar desert oasis, Alexandra Fiord, Ellesmere Island. In: Svoboda J, Freedman B (eds). Ecology of a Polar Oasis: Alexandra Fiord, Ellesmere Island, Canada. Captus University Publications: Toronto. pp 41-50.

Muc M, Freedman B, Svoboda J. (1994b). Vascular plant communities of a polar oasis at Alexandra Fiord, Ellesmere Island. In: Svoboda J, Freedman B (eds). Ecology of a Polar Oasis: Alexandra Fiord, Ellesmere Island, Canada. Captus University Publications: Toronto. pp 53-63.

Olsrud M, Melillo J, Christensen T, Michelsen A, Wallander H, Olsson P. (2004). Response of ericoid mycorrhizal colonization and functioning to global change factors. New Phytol 162: 459-469.

Parrent J, Morris W, Vilgalys R. (2006). $\mathrm{CO}_{2}$-enrichment and nutrient availability alter ectomycorrhizal fungal communities. Ecology 87: 2278-2287.

Pendall E, Bridgham S, Hanson PJ, Hungate B, Kicklighter DW, Johnson DW et al. (2004). Below-ground process responses to elevated $\mathrm{CO}_{2}$ and temperature: a discussion of observations, measurement methods, and models. New Phytol 162: 311-322.

Pregitzer KS, King JA, Burton AJ, Brown SE. (2000). Responses of tree fine roots to temperature. New Phytol 147: 105-115. 
Richter-Menge J, Overland J, Proshutinsky A, Romanovsky $\mathrm{V}$, Bengtsson L, Brigham L et al. (2006). State of the Arctic Report. Seattle, WA. NOAA OAR Special Report, NOAA/OAR/PMEL.

Ritz K, McNicol W, Nunan N, Grayston S, Millard P, Atkinson D et al. (2004). Spatial structure in soil chemical and microbiological properties in an upland grassland. FEMS Microbiol Ecol 49: 191-205.

Rygiewicz P, Martin K, Tuininga A. (2000). Morphotype community structure of ectomycorrhizas on Douglasfir (Pseudotsuga menziesii Mirb. Franco) seedlings grown under elevated atmospheric $\mathrm{CO}_{2}$ and temperature. Oecologia 124: 299-308.

Smith SE, Read DJ. (1997). Mycorrhizal Symbiosis, 2nd edn. Academic Press: San Diego, USA.

Staddon P, Heinemeyer A, Fitter A. (2002). Mycorrhizas and global environmental change: research at different scales. Plant Soil 244: 253-261.

Stenström M, Gugerli F, Henry GHR. (1997). Response of Saxifraga oppositifolia L. to simulated climate change at three contrasting latitudes. Global Change Biol 3: 44-54.

Sterenberg VZ, Stone WE. (1994). Geology of the Alexandra Fiord lowland area, Ellesmere Island, N.W.T. In: Svoboda J, Freedman B (eds). Ecology of a Polar Oasis: Alexandra Fiord, Ellesmere Island, Canada. Captus University Publications: Toronto. pp 13-22.

Sturm M, Racine C, Tape K. (2001). Climate changeincreasing shrub abundance in the arctic. Nature 411: 546-547.
Tokeshi M. (1999). Species Coexistence: Ecological and Evolutionary Perspectives. Blackwell Science, Ltd: Oxford, UK.

Urcelay C, Bret-Harte M, Diaz S, Chapin III FS. (2003). Mycorrhizal colonization mediated by species interactions in arctic tundra. Oecologia 137: 399-404.

Van Wijk MT, Clemmensen KE, Shaver GR, Williams M, Callaghan TV, Chapin III FS et al. (2004). Long-term ecosystem level experiments at Toolik Lake, Alaska, and at Abisko, northern Sweden: generalizations and differences in ecosystem and plant type responses to global change. Global Change Biol 10: 105-123.

Walker MD, Wahren CH, Hollister RD, Henry GHR, Ahlquist LE, Alatalo JM et al. (2006). Plant community responses to experimental warming across the tundra biome. Proc Natl Acad Sci USA 103: 1342-1346.

White TJ, Bruns TD, Lee S, Taylor J. (1990). Amplification and direct sequencing of fungal ribosomal RNA genes for phylogenetics. In: Innis MA, Gelfand DH, Sninsky JJ, White TJ (eds). PCR Protocols: A Guide to Methods and Applications. Academic Press: NY, USA, pp 315-321.

Zak DR, Pregitzer KS, King JS, Holmes WE. (2000). Elevated atmospheric $\mathrm{CO}_{2}$, fine roots and the response of soil microorganisms: a review and hypothesis. New Phytol 147: 201-222. 